\title{
Molecular Mechanisms Involved in Qualitative and Quantitative Resistance to the Dicarboximide Fungicide Iprodione in Sclerotinia homoeocarpa Field Isolates
}

\author{
Hyunkyu Sang, James T. Popko, Jr., Taehyun Chang, and Geunhwa Jung
}

First, second, and fourth authors: Stockbridge School of Agriculture, University of Massachusetts, Amherst, MA 01003; and third author: School of Ecology and Environmental System, College of Ecology and Environmental Science, Kyungpook National University, Sangju, 742711, Korea.

Accepted for publication 14 September 2016.

\begin{abstract}
The dicarboximide fungicide class is commonly used to control Sclerotinia homoeocarpa, the causal agent of dollar spot on turfgrass. Despite frequent occurrences of $S$. homoeocarpa field resistance to iprodione (dicarboximide active ingredient), the genetic mechanisms of iprodione resistance have not been elucidated. In this study, 15 field isolates (seven suspected dicarboximide resistant, three multidrug resistance (MDR)-like, and five dicarboximide sensitive) were used for sequence comparison of a histidine kinase gene, Shosl, of S. homoeocarpa. The suspected dicarboximideresistant isolates displayed nonsynonymous polymorphisms in codon 366 (isoleucine to asparagine) in Shosl, while the MDR-like and sensitive isolates did not. Further elucidation of the Shos 1 function, using polyethylene glycol-mediated protoplast transformation indicated that S. homoeocarpa

mutants $\left(\right.$ Shos $\left.1^{1366 \mathrm{~N}}\right)$ from a sensitive isolate gained resistance to dicarboximides but not phenylpyrrole and polyols. The deletion of Shos 1 resulted in higher resistance to dicarboximide and phenylpyrrole and higher sensitivity to polyols than Shos $1^{1366 \mathrm{~N}}$. Levels of dicarboximide sensitivity in the sensitive isolate, Shos $1^{1366 \mathrm{~N}}$, and Shos1 deletion mutants were negatively correlated to values of iprodione-induced expression of ShHogl, the last kinase in the high-osmolarity glycerol pathway. Increased constitutive and induced expression of the ATP-binding cassette multidrug efflux transporter ShPDR 1 was observed in six of seven dicarboximideresistant isolates. In conclusion, S. homoeocarpa field isolates gained dicarboximide resistance through the polymorphism in Shosl and the overexpression of ShPDR1.
\end{abstract}

Dollar spot, caused by Sclerotinia homoeocarpa (F. T. Bennett), is one of the most common and economically important diseases of cool-season turfgrass species worldwide (Smiley et al. 2005). Proper cultural management practices to turfgrass are often ineffective for complete dollar spot control. Therefore, multiple fungicide applications are often needed throughout the growing season to manage dollar spot and maintain high turf quality. However, repeated use of fungicides have led to the development of fungicide resistance in S. homoeocarpa populations (Smiley et al. 2005). Resistance to the benzimidazole and dicarboximide fungicide classes and reduced sensitivity to the sterol demethylation inhibitor (DMI) class have been reported in S. homoeocarpa field populations across North America (Cole et al. 1968; Detweiler et al. 1983; Jo et al. 2006; Miller et al. 2002; Popko et al. 2012; Putman et al. 2010). Resistance mechanisms for benzimidazole and DMI fungicides were previously elucidated in $S$. homoeocarpa (Hulvey et al. 2012; Koenraadt et al. 1992; Sang et al. 2015), whereas the one or more genetic mechanisms of dicarboximide resistance remain poorly understood.

Dicarboximide fungicides were initially introduced to control Botrytis cinerea in the late 1970s (Cui et al. 2002) and are now used to control a variety of Sclerotinia spp., Monilinia spp., and Alternaria spp. (Detweiler et al. 1983; Hutton 1988; Yoshimura et al. 2004). Iprodione and vinclozolin are two dicarboximideactive ingredients that have been registered to control dollar spot for the last three decades and played an important role in controlling

Corresponding author: G. Jung; E-mail address: jung@umass.edu

*The $\boldsymbol{e}$-Xtra logo stands for "electronic extra" and indicates that one supplementary figure and one supplementary table are published online.

(C) 2017 The American Phytopathological Society benzimidazole- and DMI-resistant populations (Detweiler et al. 1983). Dicarboximide field resistance has been reported in many plant-pathogenic fungi, such as B. cinerea (Beever and Brien 1983; Leroux et al. 2002; Katan 1982), Monilinia fructicola (Ritchie 1983), Sclerotium cepivorum (Littley and Rahe 1984), and Alternaria alternata (Hutton 1988). Genetic mechanisms responsible for dicarboximide resistance in $B$. cinerea have been well-documented and were associated with the amino acid changes in the putative target gene of iprodione, Bos 1, which encodes a class III histidine kinase (HK) involved in osmotic and oxidative stress (Ma et al. 2007). In parallel, laboratoryinduced iprodione-resistant mutants have shown cross-resistance to a phenylpyrrole fungicide, fludioxonil, and hypersensitivity to osmotic stress. Both iprodione and fludioxonil are known to affect the osmotic signal transduction cascade, but involvement of the mutations in Bos 1 in the cascade remains unresolved (Fillinger et al. 2012).

The first occurrence of iprodione field resistance in $S$. homoeocarpa was confirmed in the early 1980s by Detweiler et al. (1983). Since then, $S$. homoeocarpa isolates exhibiting resistance or reduced sensitivity to iprodione in monitored studies have been identified in the United States and Italy (Bishop et al. 2008; Jo et al. 2006; Mocioni et al. 2011; Putman et al. 2010). Putman et al. (2010) sampled 1,352 isolates from golf courses in the New England region and reported iprodione sensitivity to be quantitatively distributed for the majority of isolates but also reported a small number of "outlier" isolates with significantly reduced in vitro sensitivity levels (Putman et al. 2010). Despite reports of one or both qualitative or quantitative resistance to iprodione in $S$. homoeocarpa, the molecular mechanisms of resistance remain largely unknown. Furthermore, dicarboximide resistance mechanisms conferred by qualitative (disruptive or discrete) and quantitative (multistep or continuous) resistance within the same fungal pathogen have not been investigated. 
To examine genetic factors that contribute to a wide range of $S$. homoeocarpa iprodione sensitivity, we mined the osmosensing HK gene Shos 1 from transcriptomic data previously generated by Hulvey et al. (2012). The Shos 1 gene shares significant sequence similarity with the Bos 1 gene from B. cinerea, Mfos 1 gene from Monilinia fructicola, and Shk1 gene from Sclerotinia sclerotiorum, which have all been known to play an important role in mediating qualitative resistance to iprodione (Duan et al. 2013; Ma et al. 2006, 2007). Additionally, an ATP-binding cassette (ABC) transporter, ShPDRl, in S. homoeocarpa was previously reported to be associated with mediating quantitative resistance to iprodione (Sang et al. 2015). Sang et al. (2015) reported that $S$. homoeocarpa field isolates with reduced in vitro sensitivity to propiconazole, boscalid (SDHI: succinate dehydrogenase inhibitor), and iprodione displayed constitutive overexpression of two ABC transporters (ShatrD and ShPDRl) and only $S h P D R 1$ expression was induced in response to iprodione. ShPDRl complemented a yeast ABC transporter deletion mutant in the presence of the aforementioned three chemicals, using a yeast heterologous expression system (Sang et al. 2015). However, the direct function of the ShPDRl gene in regard to dicarboximide resistance in $S$. homoeocarpa has not been elucidated by means of genetic transformation.

The main goal of this study was to investigate the genetic determinants explaining a wide range of iprodione sensitivity using $S$. homoeocarpa field isolates, which were sampled from the aforementioned published studies (Detweiler et al. 1983; Putman et al. 2010; Sang et al. 2015). The resistance determinants were validated using a genetic transformation system based on a splitmarker approach, which was developed for the first time in $S$. homoeocarpa. The specific objectives were i) to sequence the Shosl gene of S. homoeocarpa field isolates for potential polymorphisms associated with qualitative resistance to iprodione, ii) to quantify in vitro sensitivities of isolates to iprodione, fludioxonil, propiconazole, and osmotic stress, iii) to analyze the relative expression (RE) of ShPDRl in isolates before and after iprodione exposure, and iv) to validate the function of the genes by generating Shos $1^{\mathrm{I} 366 \mathrm{~N}}$, Shos 1-knockout, and ShPDR 1 overexpression mutants from a sensitive $S$. homoeocarpa isolate and by quantifying ShHogl gene expression (last kinase of the highosmolarity glycerol [HOG] pathway) with Shos1-generated mutants.

\section{MATERIALS AND METHODS}

Fungal isolates. The origins of the $15 \mathrm{~S}$. homoeocarpa isolates used in this study are described below. One isolate (MI), which was previously confirmed to exhibit field resistance to iprodione (Detweiler et al. 1983), was collected from a creeping bentgrass putting green in Michigan. Six isolates with the highest iprodione $\mathrm{EC}_{50}$ values (the mean effective concentration for reduction of $50 \%$ mycelial growth relative to the control) were selected from a total of 387 isolates assayed in a New England monitoring study (Putman et al. 2010). The origins of these six suspected dicarboximide-resistant isolates are as follows: CT34 (West Hartford, CT), CT45 and CT47 (Wethersfield, CT), CT91 (Enfield, CT), CT189 (Simsbury, CT), and NY2 (Newburgh, NY). In addition, eight isolates collected from four golf courses with prior fungicide exposure and one baseline location, all previously characterized in field efficacy, fungicide sensitivity, and fungicide resistance mechanism studies (Popko et al. 2012; Sang et al. 2015), were chosen. Isolates HRS10, SMS23, SMI27, JTS30, and HFS35 are considered dicarboximide-sensitive, based on previous in vitro fungicide sensitivity assays (Popko et al. 2012; Sang et al. 2015). Isolates WBI7, HRI11, and HFI40 are considered MDR-like isolates and have been previously confirmed to exhibit reduced sensitivities to three chemically unrelated fungicides, propiconazole, iprodione, and boscalid (Popko et al. 2012; Sang et al. 2015). All isolates were maintained on PDA (potato dextrose agar) (Difco
Laboratories, Detroit) slant tubes at $4{ }^{\circ} \mathrm{C}$ until the study was performed.

DNA extraction, polymerase chain reaction (PCR) amplification and sequencing. Genomic DNA was extracted from all isolates, using the methods previously described by Saitoh et al. (2006) and Hulvey et al. (2012). The osmosensing HK gene Shos 1 (contig 4083; accession number JW817408) was mined from S. homoeocarpa transcriptomic data (BioProject, PRJNA167377) generated by Hulvey et al. (2012). Five primer sets were designed from Shos 1 to amplify and sequence the full-length of the Shos 1 gene (4,280 bp) for 10 isolates (CT34, CT45, CT91, CT189, NY2, MI, HRI11, HFS40, SMS23, and JTS30) and the six 1,490-bp HAMP repeats in the Shos 1 gene for five isolates (CT47, WBI7, HRS10, SMI27, and HFS40), using Primer3 (Rozen and Skaletsky 2000) (Supplementary Table S1). PCR reaction conditions followed the procedures of Sang et al. (2015). PCR amplicons were purified using ExoSAP-IT PCR cleanup reagent (Affymetrix, Santa Clara, CA) and were sequenced at the Genomic Resource Laboratory (University of Massachusetts, Amherst, MA).

Sequence and phylogenetic analyses. BLASTX and Pfam domain searches of the 3,942-bp Shosl coding sequence were conducted. Analyses of the full-length Shosl genomic sequence from 10 isolates and the six HAMP repeats of Shos 1 sequences from 15 isolates for an intron, and single nucleotide polymorphism (SNP) detection were performed using MEGA v5 (Tamura et al. 2011). The full-length amino acid sequences of Shos 1 and the reported osmosensing HK amino acid sequences of other species obtained from GenBank were used for the phylogenetic analysis. Amino acid sequences were aligned using MAFFT v7.110 with automated strategy selection and BLOSUM62 scoring matrix parameters (Katoh and Toh 2008). The aligned amino acid sequences were imported into MEGA v5, and a neighbor-joining phylogenetic analysis was performed with the Poisson model, gamma distributed rates among sites, complete deletion of missing data, and 1,000 bootstrap replicates (Tamura et al. 2011).

In vitro fungicide sensitivity and osmotic stress assays. In vitro sensitivity assays for all 15 isolates were conducted on fludioxonil, iprodione, propiconazole, and $\mathrm{NaCl}$-amended minimal medium (MM) (1 liter: $10 \mathrm{~g}$ of glucose, $1.5 \mathrm{~g}$ of $\mathrm{K}_{2} \mathrm{HPO}_{4}, 2 \mathrm{~g}$ of $\mathrm{KH}_{2} \mathrm{PO}_{4}, 1 \mathrm{~g}$ of $\left(\mathrm{NH}_{4}\right)_{2} \mathrm{SO}_{4}, 0.5 \mathrm{~g}$ of $\mathrm{MgSO}_{4} \cdot 7 \mathrm{H}_{2} \mathrm{O}, 2 \mathrm{~g}$ of yeast extract, and $12.5 \mathrm{~g}$ of agar), as per Sang et al. (2015). The iprodione and propiconazole $\mathrm{EC}_{50}$ values of five dicarboximide-sensitive isolates and three MDR-like isolates previously used by Sang et al. (2015) were re-estimated in this present study. Isolates were previously stored on PDA slant tubes $\left(4^{\circ} \mathrm{C}\right)$, were transferred to PDA, and were grown for 2 days at room temperature. Agar plugs $(5 \mathrm{~mm}$ in diameter) were extracted from active colonies and were inoculated on the edge of nonamended MM plates; iprodione $(0.01,0.1,1,10$, and $\left.100 \mu \mathrm{g} \mathrm{ml}^{-1}\right)$, fludioxonil (0.001, 0.01, 0.1, 1 , and $10 \mu \mathrm{g} \mathrm{ml}^{-1}$ ), propiconazole $\left(0.001,0.01,0.1,1\right.$, and $\left.10 \mu \mathrm{g} \mathrm{ml}^{-1}\right)$, and $\mathrm{NaCl}(0.5$ and $1 \mathrm{M})$ amended MM plates. After 8 days of incubation, the diameter from agar plug to the colony margin was measured using $16 \mathrm{EX}$ digital calipers (Mahr, Göttingen, Germany). Two separate experiments and four replicates (petri plates) per each experiment were performed for each isolate or concentration. Iprodione, fludioxonil, and propiconazole $\mathrm{EC}_{50}$ values and percent relative mycelial growth (RMG) of isolates on $\mathrm{NaCl}$-amended medium were calculated as per Jo et al. (2006).

RNA extraction, cDNA synthesis, and relative quantification of ShPDRI and ShHog1 expression. The ABC transporter ShPDRl was selected for this study, because overexpression of ShPDRl was positively correlated with reduced sensitivities to chemically unrelated fungicide classes, including dicarboximide (Sang et al. 2015). For analysis of ShPDRl expression levels, RNA samples were extracted from seven suspected dicarboximideresistant isolates and two dicarboximide-sensitive isolates (SMS23 and JTS30) before and after exposure $(1 \mathrm{~h})$ to iprodione $\left(1 \mu \mathrm{g} \mathrm{ml}{ }^{-1}\right)$ 
in this present study, using the methods detailed by Sang et al. (2015). Previously obtained $\mathrm{C}_{\mathrm{T}}$ (cycle threshold) values of ShPDRI and actin gene (Shact) for three MDR-like (WBI7, HRI11, and HFI40) and three dicarboximide-sensitive isolates (HRS10, SMI27, HFS35) were used for the purpose of comparison (Sang et al. 2015). Expression of hog1-type mitogen-activated protein kinase ShHogl, mined from S. homoeocarpa genomic data (Bioproject, PRJNA302176), generated by Green et al. (2016), was also analyzed. RNA extraction was performed on the isolate and mutants in the absence and presence of iprodione $\left(10 \mu \mathrm{g} \mathrm{ml}^{-1}\right)$ and propiconazole $\left(1 \mu \mathrm{g} \mathrm{ml}^{-1}\right)$ for $1 \mathrm{~h}$. cDNA synthesis from each sample of RNA was performed with the QuantiTect reverse transcription kit (Qiagen Inc., Valencia, CA). For relative quantification of ShPDRl and ShHogl expression, the actin gene (Shact) was selected as a housekeeping gene. The primers for ShPDRl and Shact were described by Sang et al. (2015). Relative gene expression was calculated using the comparative $\mathrm{C}_{\mathrm{T}}$ method (Livak and Schmittgen 2001). All experiments were performed with two biological replicates and three technical replicates per each biological replicate for each isolate and treatment.

Construction of vectors for Shos1-knockout, Shos1 $1^{1366 N}$, and overexpression of ShPDR1. The hygromycin resistance cassette PtrpC-hph was amplified from pYHN3 (Rech et al. 2007), using F_ptrpC and R_hph, and was cloned into pCR2.1-TOPO (Invitrogen, Carlsbad, CA), resulting in the plasmid Topo-hph. A 1-kb upstream flanking sequence of Shosl was amplified from genomic DNA (gDNA) of isolate HRS10, using primer F_KpnI_upos1 and R_SpeI_upos1. The amplicon was inserted into the KpnI and SpeI sites of the plasmid Topo-hph to generate the plasmid Topo-hph-upos1. Subsequently, a 1-kb downstream flanking sequence of Shosl amplified from gDNA of isolate HRS10 using the primers F_NotI_downos1 and R_ApaI_downos1 was inserted into NotI and ApaI sites of the plasmid Topo-hphupos1 to generate the plasmid Topo- $\Delta$ Shos1. As a result, the Shos 1 deletion vector Topo- $\Delta$ Shos 1 was constructed by inserting $1 \mathrm{~kb}$ of two flanking sequences of the Shosl gene into both sides of PtrpChph in the Topo-hph vector. Two constructs were amplified with primers F_upos1/R_YG and F_HY/R_downos1, respectively, each containing $1 \mathrm{~kb}$ of upstream flank of the Shos 1 and $731 \mathrm{bp}$ of hph or $1 \mathrm{~kb}$ of downstream flank of the Shos 1 and 1,126 bp of PtrpC-hph (Fig. 1A). Two constructs were gel-purified using the Zymoclean gel DNA recovery kit (Zymo Research, Irvine, CA). For construction of Shos 1 I366N vector, the full length of Shos 1 gDNA from dicarboximide-resistant isolates CT45 was amplified, using a primer set F_KpnI_Shos1 and R_SpeI_Shos1. The purified Shos 1 fragment was inserted into KpnI and SpeI sites of the plasmid Topo- $\Delta$ Shos1 to generate the plasmid Topo-Shos $1^{1366 N}$. Both constructs were amplified with primers, F_Shos1/R_YG and F_HY/R_downos1, respectively.

To construct a gene overexpression plasmid for $S$. homoeocarpa (pYHN3-pShEF1 $\alpha$ ), the plasmid pYHN3 (Rech et al. 2007) was modified by insertion of a multiple cloning site from pYES2 (Invitrogen, Carlsbad, CA), using primer set F_NcoI_MCS and R_SpeI_MCS and $1 \mathrm{~kb}$ of the upstream region of elongation factor 1 alpha $(\operatorname{ShEF1} \alpha)$ from gDNA of isolate HRS10, using primer set F_ApaI_ShpEF1 $\alpha$ and R_NcoI_ShpEF1 $\alpha$. The full length of ShPDR1 coding region amplified from plasmid pYES2-ShPDR1 (Sang et al. 2015) using F_KpnI_PDR1 and R_SpeI_PDR1 was inserted into the vector pYHN3-pShEF1 $\alpha$, which resulted in a ShPDR1 overexpression vector pYHN3-pShEF1 $\alpha$-ShPDR1.

Protoplast preparation and transformation of $S$. homoeocarpa. The method for protoplast preparation and transformation of $S$. homoeocarpa was modified from Rollins (2013). In brief, mycelia of $S$. homoeocarpa isolate HRS10 were grown on PDA for 4 days

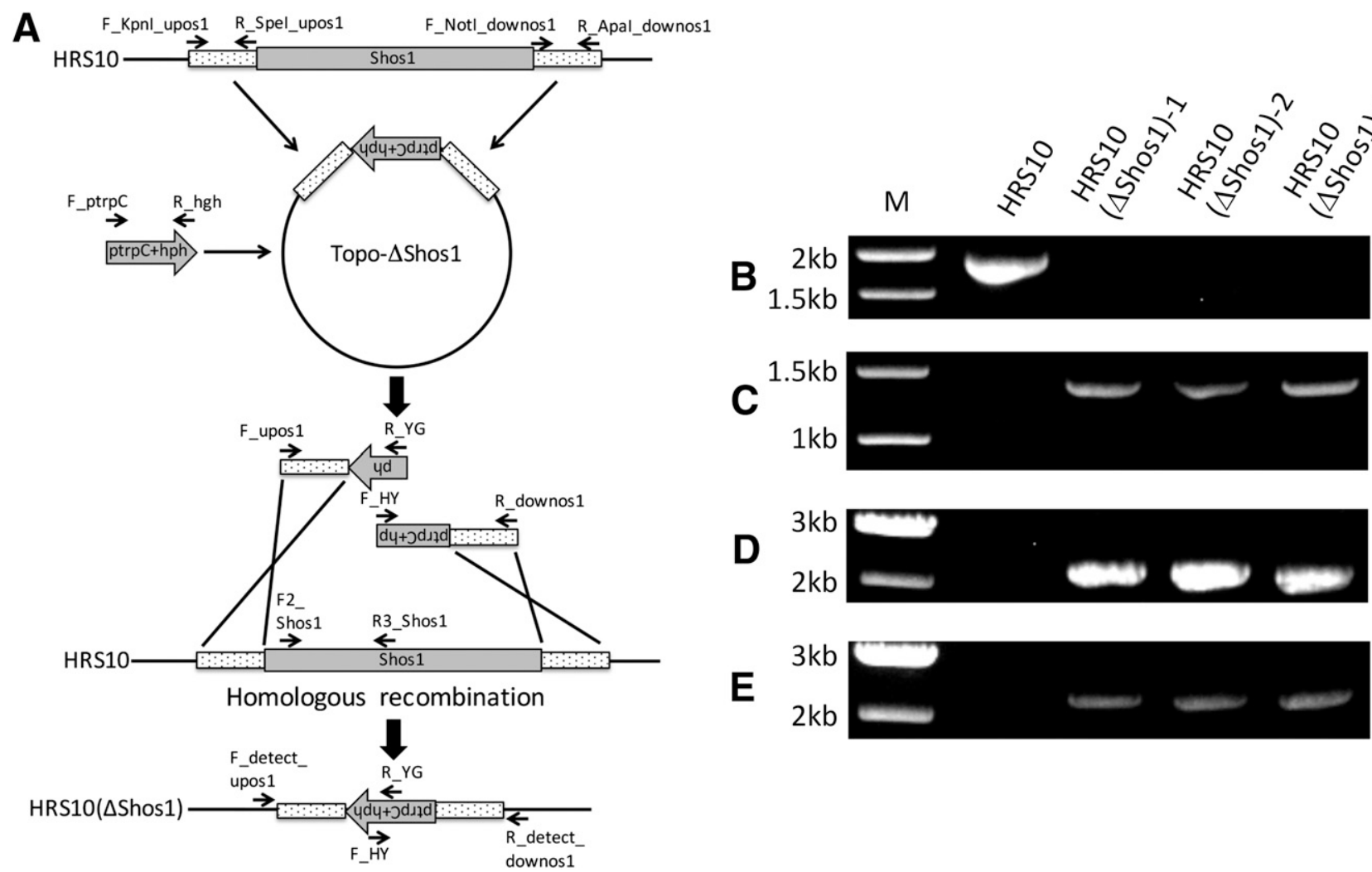

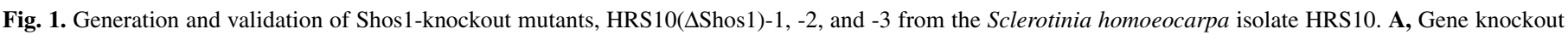

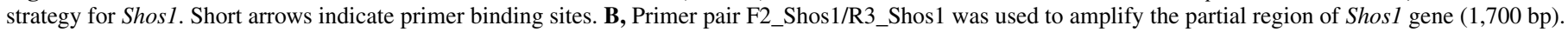

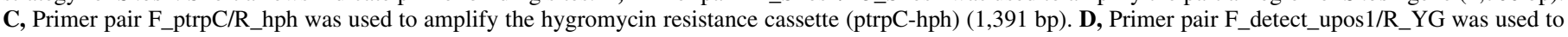

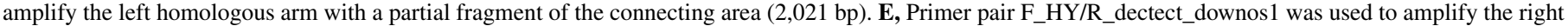
homologous arm with a partial fragment of the connecting area (2,270 bp). M denotes molecular mass markers of the 1-kb ladder. 
and were then inoculated in a 50-ml falcon tube (USA Scientific Inc., Ocala, FL) containing $25 \mathrm{ml}$ of potato dextrose broth (Becton Dickinson, Franklin Lakes, NJ) and were incubated for 4 days at $23^{\circ} \mathrm{C}$, without agitation. The mycelia were collected from four layers of sterile cheesecloth in a funnel, were washed with sterile water and then with protoplast buffer $\left(0.8 \mathrm{M} \mathrm{MgSO}_{4} \cdot 7 \mathrm{H}_{2} \mathrm{O}, 0.2 \mathrm{M}\right.$ $\mathrm{C}_{6} \mathrm{H}_{5} \mathrm{Na}_{3} \mathrm{O}_{7} \cdot 2 \mathrm{H}_{2} \mathrm{O}, \mathrm{pH}$ 5.5). The washed mycelia were cut into smaller pieces and were placed into a sterile 250-ml Erlenmeyer flask. Lysing enzymes $(200 \mathrm{mg}$ ) from Trichoderma harzianum (Sigma-Aldrich, St. Louis) were dissolved in $3 \mathrm{ml}$ of buffer (1 M

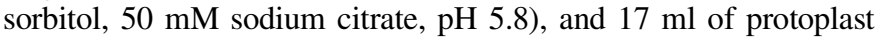
buffer was added to the mycelium-containing Erlenmeyer flask. The flask was incubated at $28^{\circ} \mathrm{C}$, with $100 \mathrm{rpm}$ of agitation on a shaker for $3 \mathrm{~h}$. The solution containing protoplasts was filtered through sterile cheesecloth and was collected in a sterile 250-ml Erlenmeyer flask. Next, $30 \mathrm{ml}$ of $0.6 \mathrm{M} \mathrm{KCl}$ was added to the cheesecloth and was collected in the flask containing protoplast. The protoplast solution was transferred into a 50-ml falcon tube and was centrifuged for $10 \mathrm{~min}$ at $4^{\circ} \mathrm{C}(3,000 \times \mathrm{g})$. The pelleted protoplasts were washed twice with $10 \mathrm{ml}$ of STC buffer (1 M sorbitol, $50 \mathrm{mM}$ Tris, $\mathrm{pH} 8$, $\left.50 \mathrm{mM} \mathrm{CaCl} \cdot 2 \mathrm{H}_{2} \mathrm{O}\right)$. Protoplast solution $(500 \mu \mathrm{l})\left(1 \times 10^{7}\right.$ protoplasts per milliliter in STC buffer), $6.25 \mu \mathrm{l}$ of dimethyl sulfoxide, $31.25 \mu \mathrm{l}$ of heparin ( $5 \mathrm{mg} \mathrm{ml}^{-1}$ prepared in STC buffer), and $125 \mu$ l of polyethylene glycol (PEG) solution (40\% PEG 3350, $50 \mathrm{mM}$ Tris, $\mathrm{pH} 8,0.6 \mathrm{M} \mathrm{KCl}, 50 \mathrm{mM} \mathrm{CaCl}_{2}$ ) were added to a $1.5-\mathrm{ml}$ microcentrifuge tube and were then stored at $-80^{\circ} \mathrm{C}$.

For the transformation of $S$. homoeocarpa, protoplasts stored at $-80^{\circ} \mathrm{C}$ were thawed on ice and $2 \mu \mathrm{g}$ of split marker construct or $4 \mu \mathrm{g}$ of plasmid was added to the tube. The tube was incubated on ice for $60 \mathrm{~min}$, and then, $1 \mathrm{ml}$ of PEG solution was added. The mixture was incubated at room temperature for $20 \mathrm{~min}$. The protoplasts were transferred into a 15-ml screw-cap falcon tube (USA Scientific Inc.) and $5 \mathrm{ml}$ of regeneration medium ( $239.6 \mathrm{~g}$ of sucrose, $0.5 \mathrm{~g}$ of yeast extract per liter) were added. The tube was incubated for 12 to $16 \mathrm{~h}$ at room temperature on a Bigger Bill digital oscillator (Thermo Scientific Thermolyne, Waltham, MA) at $150 \mathrm{rpm}$. The tube was centrifuged at $2,500 \times g$ for $10 \mathrm{~min}$ at $4{ }^{\circ} \mathrm{C}$, and the supernatant was discarded. The protoplasts were resuspended with $200 \mathrm{ml}$ of STC buffer in the tube and were spread on regeneration agar medium containing $100 \mu \mathrm{g} \mathrm{ml}^{-1}$ of hygromycin B (Invitrogen, Carlsbad, CA). Upon selection on hygromycin media for 4 to 8 days at $23^{\circ} \mathrm{C}$, transformants were obtained and then hyphal tip-transferred to PDA containing $100 \mu \mathrm{g} \mathrm{ml}^{-1}$ of hygromycin B at least three times.

In vitro sensitivity assays and pathogenicity tests of Shos1knockout, Shos1 ${ }^{1366 \mathrm{~N}}$, and ShPDR1 overexpressed mutants. In vitro sensitivity assays were conducted on the two Shos1-knockout mutants [HRS10( $\Delta$ Shos1)-1 and HRS10( $\Delta$ Shos1)-2], two Shos1 1366N mutants [HRS10(Shos $\left.1^{1366 \mathrm{~N}}\right)-1$ and HRS10(Shos1 $\left.\left.{ }^{\mathrm{I366N}}\right)-2\right]$, two PDR1 overexpression mutants [HRS10(ShPDR1 OX)-1 and HRS10(ShPDR1 OX)2], and four isolates (HRS10, HRI11, CT45 and NY2) with iprodione, vinclozolin, and fludioxonil. Shos1-knockout, Shos 1 ${ }^{\mathrm{I} 666 \mathrm{~N}}$, and ShPDR1 overexpression mutants and HRS10 were also used for in vitro sensitivity assays with $\mathrm{NaCl}, \mathrm{KCl}$, glucose, D-sorbitol, and $\mathrm{H}_{2} \mathrm{O}_{2}$. An agar plug (diameter, $4 \mathrm{~mm}$ ) from each isolate grown on PDA for 3 days was inoculated on nonamended MM, iprodione $\left(1.5,3,15\right.$, and $\left.25 \mu \mathrm{g} \mathrm{ml}^{-1}\right)$, vinclozolin $\left(1\right.$ and $\left.5 \mu \mathrm{g} \mathrm{ml}^{-1}\right)$, fludioxonil $\left(0.1 \mu \mathrm{g} \mathrm{ml}^{-1}\right), \mathrm{NaCl}(0.4 \mathrm{M}), \mathrm{KCl}(0.2 \mathrm{M})$, glucose (1 M), D-sorbitol $(1.2 \mathrm{M})$, and $\mathrm{H}_{2} \mathrm{O}_{2}(10 \mathrm{M})$ amended MM. For the calculation of RMG (\%) value, the agar plug from each isolate was also inoculated on the individual MM. After the plates had been incubated at $25^{\circ} \mathrm{C}, \mathrm{RMG}$ of each isolate was measured after 42, 62, and $144 \mathrm{~h}$, and pictures were taken. The experiment was repeated three times.

For testing pathogenicity, creeping bentgrass (cv. Penncross) was grown in a greenhouse at $18^{\circ} \mathrm{C}$ day and $16^{\circ} \mathrm{C}$ night temperatures with a 12 -h photoperiod and at $70 \%$ relative humidity. Six leaf blades from 2-month-old bentgrass plants were excised and were placed on sterile water-saturated filter paper (Whatman, Maidstone, U.K.) in $9-\mathrm{cm}$ petri dishes. An agar plug (4 $\mathrm{mm}$ in diameter) extracted from active mycelial colonies of $S$. homoeocarpa isolates (HRS10, HRI11, and CT45) and Shos1-knockout, Shos1 ${ }^{1366 N}$, and ShPDR1 ${ }^{\text {OX }}$ transformants grown on PDA was placed on the center of leaf blades. Inoculated leaf blades were incubated at $23^{\circ} \mathrm{C}$ at $100 \%$ relative humidity in the culture room. The lesion diameter on individual leaf blades was measured 2 days after inoculation. The whole experiment was repeated twice.

Statistical analysis of in vitro sensitivity assay and quantitative PCR data. For statistical analysis of in vitro sensitivity, field isolates examined were categorized into three groups according to the presence or absence of I366 N mutation and overexpression of ShPDR1 (Table 1). First, group 1 (dicarboximide-resistant isolates CT34, CT45, CT47, CT91, CT189, NY2, and MI), containing the I366 N mutation in Shos1, and groups 2 (MDR-like isolates WBI7, HRI11, and HFI40) and 3 (dicarboximide-sensitive isolates: HRS10, SMI27, SMS23, JTS30 and HFS35), not containing I366 N in Shos 1, were compared. Furthermore, group 2, showing constitutive and induced overexpression of ShPDRl, and group 3, showing no constitutive and induced overexpression of $\operatorname{ShPDR} 1$, were compared. Analysis of variance (ANOVA) and Fisher's protected least significant difference (LSD) were conducted to compare mean $\mathrm{EC}_{50}$ and percent $\mathrm{RMG}$ values between the aforementioned groups. ANOVA was conducted on RE values for ShPDRl between group 1 and group 2 and between group 1 and group 3. Linear regression analysis was conducted with iprodione $\mathrm{EC}_{50}$ values and $\log _{10}$-transformed mean RE values of ShPDRl constitutive expression for all 15 isolates.

ANOVA and Fisher's protected LSD were conducted to compare mean percent RMG values among 10 isolates (HRS10, HRI11, CT45, NY2, and two Shos $1^{1366 \mathrm{~N}}$, two Shos1-kockout, and two ShPDR1 overexpression mutants), percent RMG values among four isolates (HRS10, HRI11, and two ShPDR1 overexpression mutants), percent RMG values among four isolates (HRS10, and Shos $1^{1366 N}$, Shos1-kockout, ShPDR1 overexpression mutants), and mean lesion diameter among nine isolates (HRS10, HRI11, CT45, and two Shos11366N, two Shos1-kockout, and two ShPDR1 overexpression mutants). Last, ANOVA was conducted on fold induction values for $\mathrm{ShHog} 1$ expression between HRS10 and the Shos $1^{1366 \mathrm{~N}}$ mutant and between HRS10 and the Shos1-knockout mutant. All statistical analyses were conducted using the JMP software package, version 10.0 (SAS Institute Inc., Cary, NC).

\section{RESULTS}

Sequence and phylogenetic analyses. The HK gene Shos 1 from $S$. homoeocarpa was characterized by BLAST search, Pfam domain, phylogenetic analyses, and sequencing to detect potential polymorphisms associated with dicarboximide resistance. A BLASTX search revealed that Shos1 shares high homology with three genes encoding a HK two-component regulatory system, Shkl from Sclerotinia sclerotiorum (accession number EDN97840), Mfos1 from Monilinia fructicola (accession number ABF60145), and Bos1 from B. cinerea (accession number AFQ90105). These genes have been reported to mediate resistance to the dicarboximide fungicide class (Cui et al. 2004, 2002; Duan et al. 2013; Ma et al. 2006, 2007; Oshima et al. 2002) and were identified by an E-value of 0 and coding sequence coverage of $99 \%$. The Shos 1 sequence shares $94 \%$ of amino acid identity with Shk1 (1,234 out of 1,310), Mfos1 (1,237 out of 1,317), and Bos1 (1,234 out of 1,316). Six HAMP repeat domains, one kinase domain, and one response regulator domain were detected by a Pfam domain search. Phylogenetic analysis showed that Shos1, Shk1, Mfos1, and Bos1 are placed in the same clade and were supported by a high bootstrap value (100\%) (Supplementary Fig. S1). The Shosl coding sequence from HRI11 was deposited in GenBank with accession number KM576215. 
Comparison of sequences obtained from gDNA sequencing and transcriptomic data indicated that the 4,280 bp of Shosl is interrupted by six introns. The SNP detection analysis of the full length of Shosl gene from 10 isolates indicated that only polymorphisms at codon 366 , located in the second repeat of HAMP domain of Shos1, are perfectly correlated to suspected dicarboximide-resistant isolates. Further sequence analysis of six
HAMP repeats $(1,490 \mathrm{bp})$ in the Shosl gene from 15 isolates revealed that ATC at codon 366 in MDR-like and sensitive isolates was replaced by AAT in resistant isolates CT34, CT45, CT47, CT91, and CT189, and by AAC in resistant isolates MI and NY2. However, these altered nucleotides encoding the same amino acid change an isoleucine to an asparagine at codon 366 (I366 N) (Fig. 2).

TABLE 1. In vitro sensitivity of Sclerotinia homoeocarpa isolates to fungicides and $\mathrm{NaCl}$ and mean comparison of the sensitivity among three groups of isolates

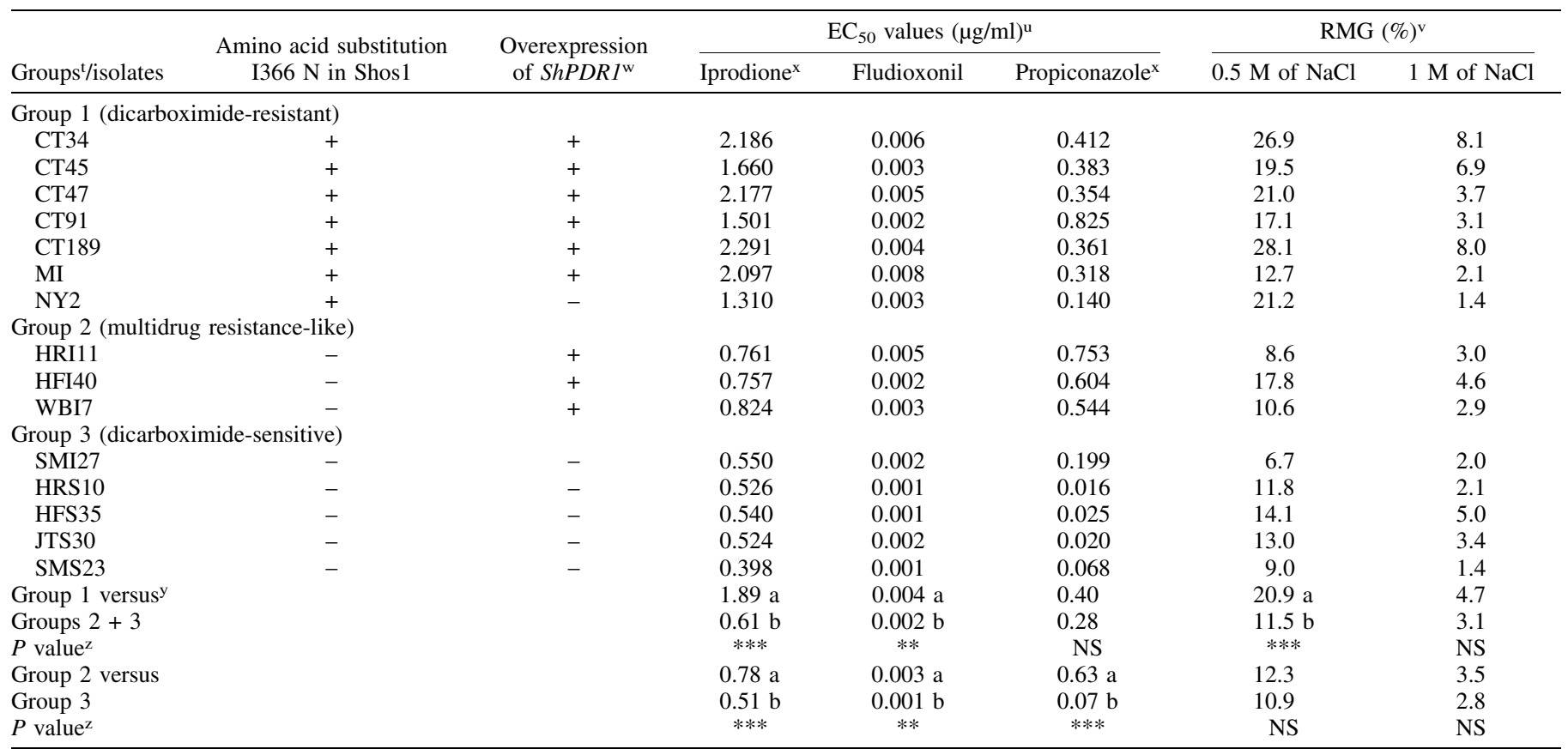

${ }^{\mathrm{t}}$ Field isolates were grouped based on presence (+) or absence (-) of amino acid substitution I366 N and overexpression of ShPDR1 as follows: Group 1 (dicarboximide-resistant), Group 2 (multidrug resistance-like), and Group 3 (dicarboximide-sensitive).

u $\mathrm{The}^{\mathrm{E}} \mathrm{EC}_{50}$ value is the effective fungicide concentration inhibiting mycelial growth of the isolates on fungicide-amended media by $50 \%$ compared with growth on nonamended media.

$\checkmark$ Relative mycelial growth (RMG) (\%) was calculated by dividing the mean colony diameter of isolate on minimal medium (MM) amended with 0.5 or $1 \mathrm{M}$ of $\mathrm{NaCl}$ by the mean colony diameter of isolate grown on nonamended $\mathrm{MM}$.

${ }^{\mathrm{w}}$ Isolates (+) showed a higher constitutive expression of ShPDR1 than the control isolate (SMS23) and higher induced expression of ShPDR1.

${ }^{\mathrm{x}}$ Iprodione and propiconazole $\mathrm{EC}_{50}$ values of Group 2 and Group 3 isolates adapted from Sang et al. (2015) were presented.

${ }^{y}$ Means followed by the same letter are not significantly different according to Fisher's protected least significant difference test $(\alpha=0.05)$.

z Asterisks (** and $* * *$ ) represent significant difference at $P<0.01$ and 0.001 , respectively. NS, not significant.

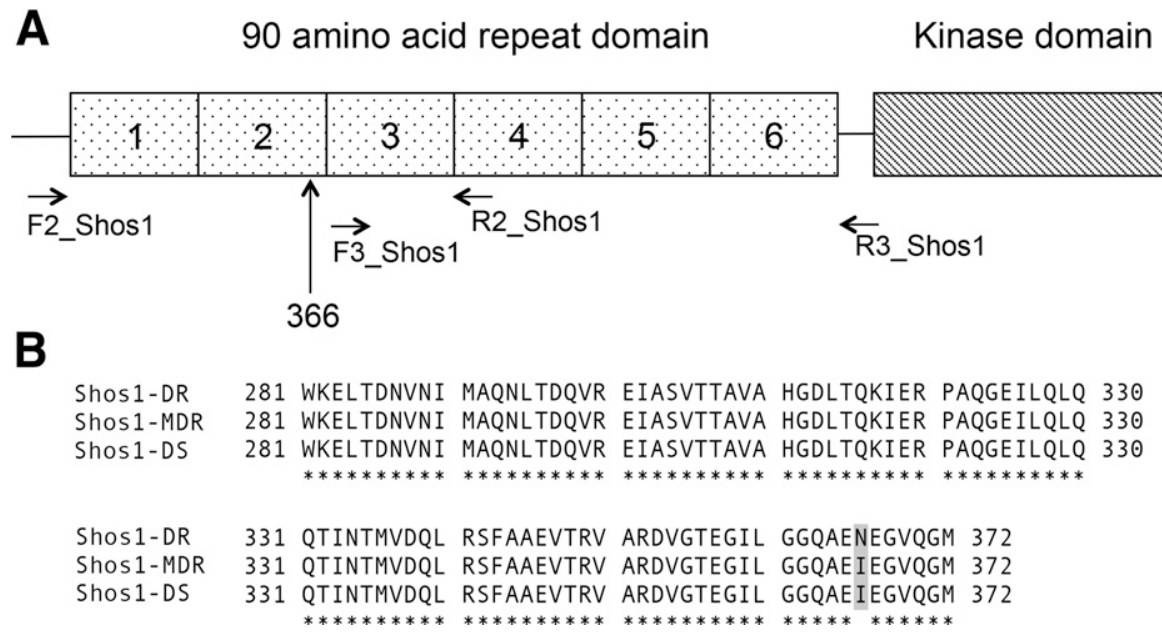

Fig. 2. A, Schematic diagram of the partial Shos 1 gene structure showing the location of primers used in this study. The vertical arrow indicates a substitution at amino acid position 366 of the Shos 1 gene in dicarboximide-resistant isolates of Sclerotinia homoeocarpa. B, Alignment of partial deduced amino acid sequence of Shos1 gene from dicarboximide-resistant (Shos1-DR), multidrug resistance-like (Shos1-MDR), and dicarboximide-sensitive (Shos1-DS) isolates of S. homoeocarpa. The shaded letters indicate the change at amino acid position 366 correlated with resistance to iprodione in dicarboximide-resistant isolates. Asterisks indicate identical amino acids among the isolates compared. 
Sensitivity of $S$. homoeocarpa isolates to fungicides and osmotic stress. The in vitro sensitivity of 15 individual field isolates to iprodione (dicarboximide), propiconazole (DMI), fludioxonil (phenylpyrrole), and $\mathrm{NaCl}$ (osmotic stress) were assayed and are presented in Table 1. Furthermore, mean $\mathrm{EC}_{50}$ values among group 1 (dicarboximide-resistant), group 2 (multidrug resistance-like), and group 3 (dicarboximide-sensitive) were compared with correlate genetic determinants with their sensitivity levels. The mean iprodione $\mathrm{EC}_{50}$ values for group 1 (isolates containing I366 $\mathrm{N}$ mutation in Shos1) were significantly higher than mean iprodione $\mathrm{EC}_{50}$ values of groups 2 and 3 (isolates that did not contain I366 N mutation in Shos1). In addition, group 2 (isolates that overexpressed ShPDR1) had significantly higher mean iprodione $\mathrm{EC}_{50}$ values than group 3 isolates. Although group 1 had statistically higher mean fludioxonil $\mathrm{EC}_{50}$ values than combined groups 2 and 3 , the $\mathrm{EC}_{50}$ values were numerically low in all individual isolates and, most likely, were biologically insignificant (Table 1). The mean propiconazole $\mathrm{EC}_{50}$ values in group 2 were significantly higher than the ones in group 3 .

The mean percent RMG values in group 1 on $0.5 \mathrm{M} \mathrm{NaCl}$ amended MM were significantly higher than those of both groups 2 and 3; however, isolate MI in group 1 had a similar RMG value to group 3 isolates. There is no statistical difference among the three groups on $1 \mathrm{M} \mathrm{NaCl}$ amended MM (Table 1).

Quantitative reverse transcription (qRT)-PCR analysis of ShPDR1. To test the possible involvement of ShPDRl overexpression in iprodione resistance, mean RE values of ShPDRl in group 1 isolates were compared with mean RE values of groups 2 and 3. Group 1 (mean $=10.69 \pm 0.68$ standard error $[\mathrm{SE}])$ showed significantly higher constitutive RE values of ShPDR 1 than group 3 (mean $=1.40 \pm 0.72 \mathrm{SE})(P<0.0001)$ but was not significantly different from group 2 (mean $=9.02 \pm 1.15 \mathrm{SE})(P=0.25)$. In the presence of iprodione $(1 \mu \mathrm{g} \mathrm{ml}-1)$, group 1 isolates exhibited increased RE of ShPDR1, with the exception of isolate NY2. In contrast, increased RE of ShPDRl was not observed in isolates JTS30 and SMS23 (group 3), behaving as the other dicarboximidesensitive isolates previously characterized for ShPDR 1 expression (Sang et al. 2015) (Fig. 3).

Linear regression of $S h P D R 1$ expression and $\mathrm{EC}_{50}$ values for iprodione. The linear regression analysis was performed to examine whether constitutive expression of ShPDRl is correlated

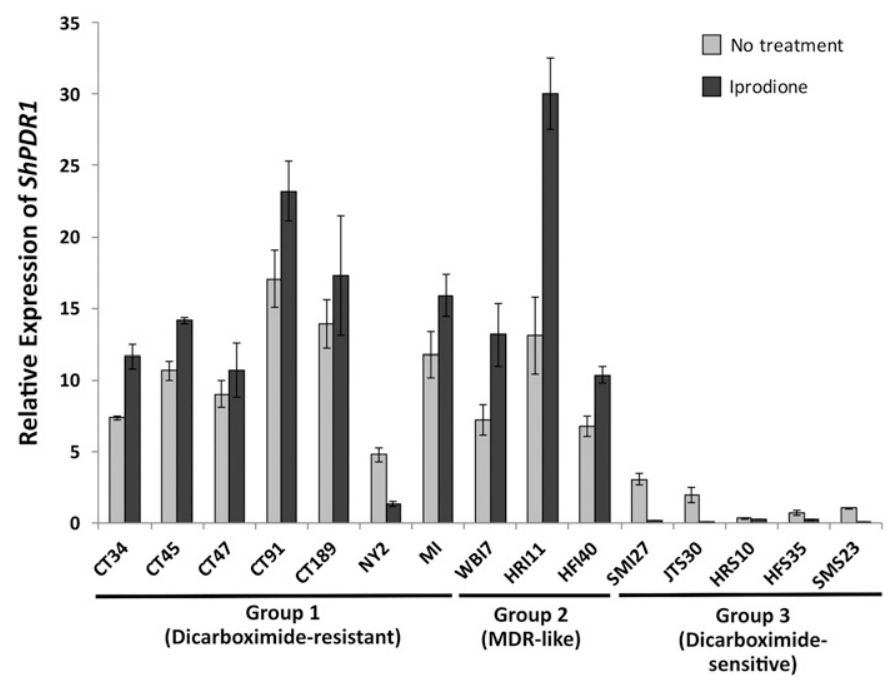

Fig. 3. Relative expression (RE) of ShPDRl in 15 field isolates before and after exposure to iprodione $\left(1 \mu \mathrm{g} \mathrm{m}^{-1}\right)$ for $1 \mathrm{~h}$. Light and dark gray bars indicate mean constitutive RE values and mean iprodione-induced RE values, respectively. Error bars represent one standard error from the mean. For comparison purposes, ShPDR1 expression values of multidrug resistance (MDR)-like and three dicarboximide-sensitive isolates adapted from Sang et al. (2015) were reanalyzed and presented. with iprodione sensitivity. The linear relationship between $\log _{10^{-}}$ transformed mean $\mathrm{RE}$ values for $S h P D R 1$ and $\mathrm{EC}_{50}$ values of iprodione was significant $(P=0.0058)$. The dicarboximide-resistant isolates with both $S h P D R 1$ overexpression and Shos1 mutation, except for isolate $\mathrm{NY} 2$, showed higher iprodione $\mathrm{EC}_{50}$ values than MDR-like isolates with ShPDRl overexpression alone (Fig. 4).

Generation of Shos1-knockout, Shos1 $1^{1366 N}$, and ShPDR1 overexpression mutants of $S$. homoeocarpa. For functional validation of Shosl and ShPDRl genes, we generated Shos1knockout, Shos $1^{1366 \mathrm{~N}}$, and ShPDR1 overexpression mutants from sensitive $S$. homoeocarpa isolate HRS10. Among 24 hygromycinresistant transformants, three Shos1-knockout mutants were confirmed by PCR with four primer pairs. A 1,700-bp partial region in the Shos 1 gene was only amplified in isolate HRS10, using the primer pair F2_Shos1 and R3_Shos1 (Fig. 1B). A pair of primers, F_ptrpC and R_hph, were used to amplify a 1,391-bp region of PtrpC$\mathrm{hph}$, which was only detected in three Shos1-knockout mutants $\operatorname{HRS10}(\Delta \operatorname{Shos} 1)-1, \operatorname{HRS} 10(\Delta \operatorname{Shos} 1)-2$, and HRS10( $\Delta$ Shos1)-3 (Fig. 1C). A 2,021-bp section of the left flanking region and a 2,270-bp section of right flanking region were amplified in three Shos1knockout mutants, using two pairs of primers, F_detect_upos1/R_YG and F_HY/R_dectect_downos1, respectively (Fig. 1D and E).

From 18 hygromycin-resistant transformants, three Shos $1^{1366 N}$ mutants were confirmed by the aforementioned method, using primer sets F_ptrpC/R_hph, F5_Shos1/R_YG, and F_HY/ R_dectect_downos1. The analysis of the full-length Shos 1 gene sequence from three Shos $1^{1366 \mathrm{~N}}$ mutants indicated that ATC at codon 366 in isolate HRS10 was replaced by AAT in the three mutants.

Two ShPDR1 overexpression mutants that exhibited the highest RMG values on iprodione $\left(1.5 \mu \mathrm{g} \mathrm{ml}^{-1}\right)$ were selected from 45 hygromycin-resistant transformants. The total RNA of two ShPDR1 overexpression mutants, HRS10(ShPDR1OX)-1 and HRS10(ShPDR1 ${ }^{\text {OX }}$ )-2, and HRS10 were extracted for comparison of the RE of ShPDR1. The HRS10(ShPDR1OX)-1 and HRS10 (ShPDR1OX)-2 mutants showed 3- to 5.6-fold increased expression of ShPDRl over the sensitive isolate HRS10.

In vitro sensitivity to fungicides, osmotic and oxidative stress, and pathogenicity tests of Shos1-knockout, Shos1 ${ }^{1366 N}$ and ShPDR1 overexpression mutants of $S$. homoeocarpa. The previously described mutants and field isolates were assayed on different fungicide classes, osmotic, and oxidative stresses. The

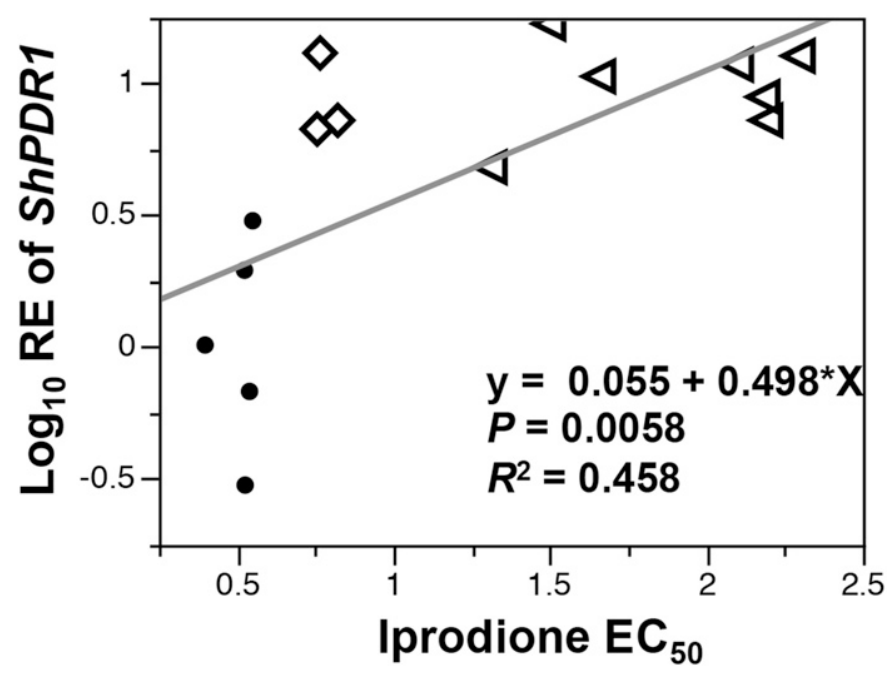

Fig. 4. Relationship between $\log _{10}$ relative expression (RE) values of ShPDRI and iprodione $\mathrm{EC}_{50}$ values for 15 field Sclerotinia homoeocarpa isolates. Triangles denote dicarboximide resistant isolates (Group 1), diamonds denote multidrug resistance-like isolates (Group 2), and dots denote dicarboximidesensitive isolates (Group 3). 
HRS10( $\triangle$ Shos1)-1 and HRS10( $\triangle$ Shos1)-2 mutants, HRS10(Shos 1 $\left.{ }^{1366 \mathrm{~N}}\right)-1$ and HRS10(Shos $\left.1^{1366 N}\right)-2$ mutants, and dicarboximide-resistant isolates (NY2 and CT45) showed resistance to iprodione at $3 \mu \mathrm{g}$ $\mathrm{ml}^{-1}$ and vinclozolin at $1 \mu \mathrm{g} \mathrm{ml}^{-1}$ (Fig. 5A). Furthermore, Shos1knockout mutants and CT45 containing the mutation in Shos 1 and overexpression of ShPDRl showed resistance to iprodione at $15 \mu \mathrm{g}$ $\mathrm{ml}^{-1}$; however, only Shos1-knockout mutants showed resistance to iprodione at $25 \mu \mathrm{g} \mathrm{ml}^{-1}$, vinclozolin at $5 \mu \mathrm{g} \mathrm{ml}^{-1}$, and fludioxonil at $0.1 \mu \mathrm{g} \mathrm{ml}^{-1}$. Since Shos1-knockout and Shos $1^{1366 \mathrm{~N}}$ mutants and dicarboximide-resistant isolates grew quickly on media amended with $1.5 \mu \mathrm{g} \mathrm{ml}-1$ of iprodione, only four strains per plate, i.e., HRS10(ShPDR1 ${ }^{\text {OX }}$ )- 1 and HRS10(ShPDR1 ${ }^{\text {OX }}$ )-2, HRS10, and HRI11, were compared at this concentration. ShPDR1 overexpression mutants HRS10(ShPDR1OX)-1 and HRS10 (ShPDR1 ${ }^{\mathrm{OX}}$ )-2 and MDR-like isolate HRI11 showed reduced sensitivity to iprodione at $1.5 \mu \mathrm{g} \mathrm{ml}^{-1}$ (Fig. 5A). For osmotic and oxidative stresses, only the Shos1-knockout mutants showed increased sensitivity to glucose at $1 \mathrm{M}$ and sorbitol at $1.2 \mathrm{M}$ (Fig. 5B).

In addition, the pathogenicity of mutants and field isolates mentioned above was assayed on detached leaf blades of creeping bentgrass. All isolates and mutants were able to cause infection on leaf blades, with average lesion size ranging from 19 to $22 \mathrm{~mm}$ 2 days after inoculation, but no statistical difference was observed $(P=0.65)$.

RE of ShHog1 in Shos1-knockout and Shos1 ${ }^{1366 \mathrm{~N}}$ mutants. The function of Shos1 was further characterized by quantifying expression of ShHogl in Shos1 mutants and the sensitive isolate. The qRT-PCR assay indicated that ShHogl expression was upregulated by iprodione treatment in HRS10 (sixfold increase), HRS10(Shos $\left.1^{1366 N}\right)-1$ (4.4 fold increase), and HRS10( $\Delta$ Shos1)-1 (1.4 fold increase), which were statistically significant $(P<0.0001)$. Propiconazole treatment did not induce expression of ShHogl in

A

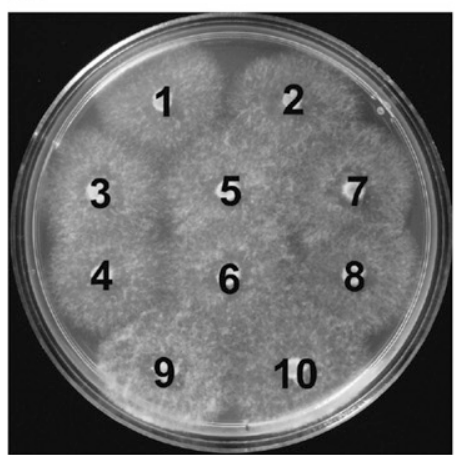

Control

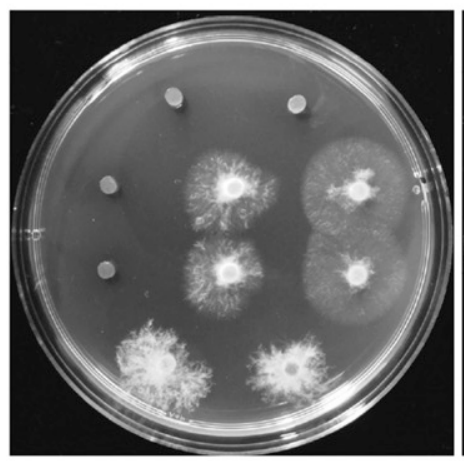

Iprodione $(3 \mu \mathrm{g} / \mathrm{ml})$

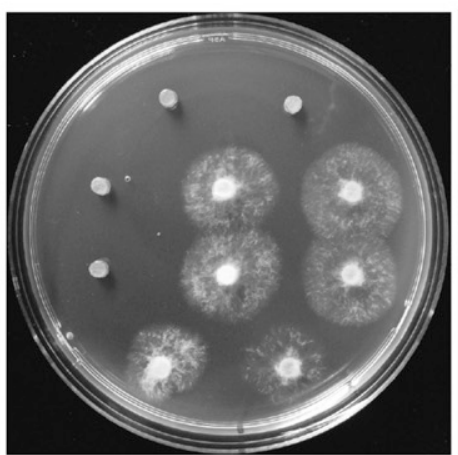

Vinclozolin $(1 \mu \mathrm{g} / \mathrm{ml})$

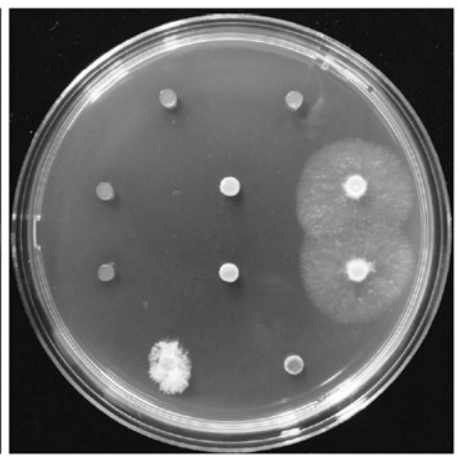

Iprodione $(15 \mu \mathrm{g} / \mathrm{ml})$

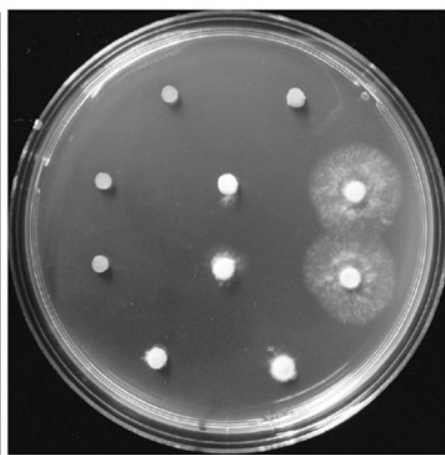

Vinclozolin $(5 \mu \mathrm{g} / \mathrm{ml})$

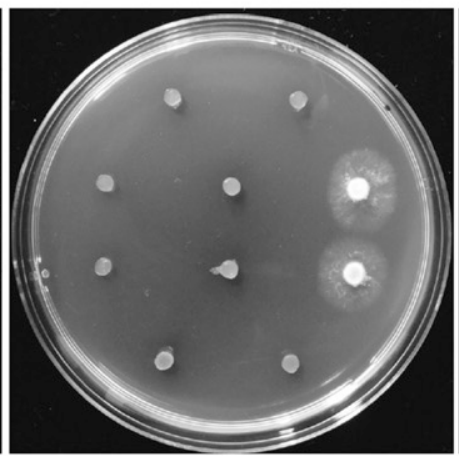

Iprodione $(25 \mu \mathrm{g} / \mathrm{ml})$

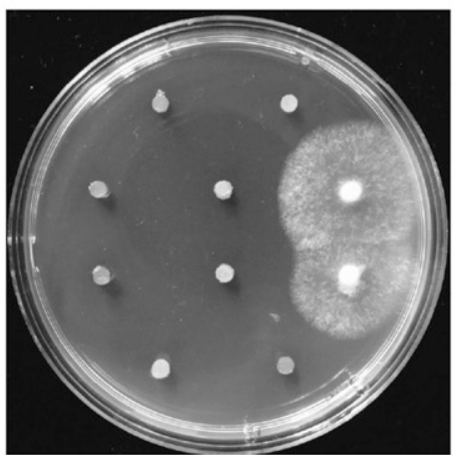

Fludioxonil $(0.1 \mu \mathrm{g} / \mathrm{ml})$

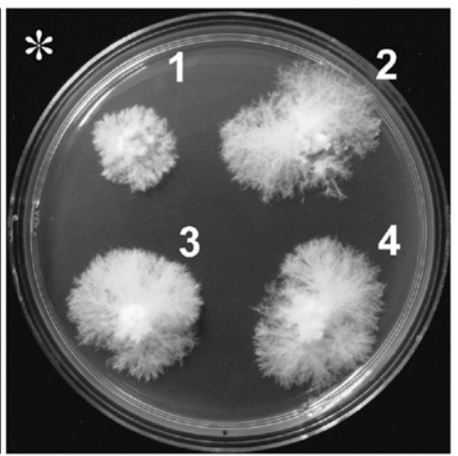

Iprodione $(1.5 \mu \mathrm{g} / \mathrm{ml})$

\section{B}

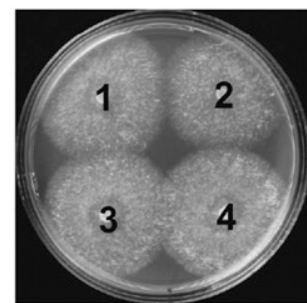

Control

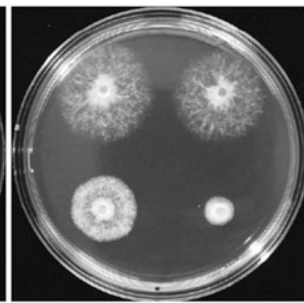

Glucose (1 M)

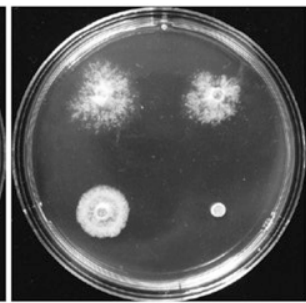

Sorbitol (1.2 M)

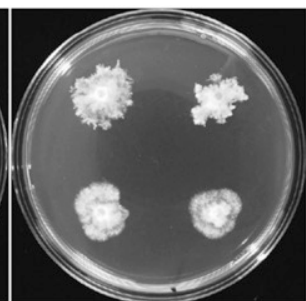

$\mathrm{NaCl}(0.4 \mathrm{M})$

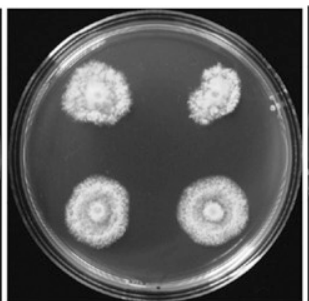

$\mathrm{KCl}(0.2 \mathrm{M})$

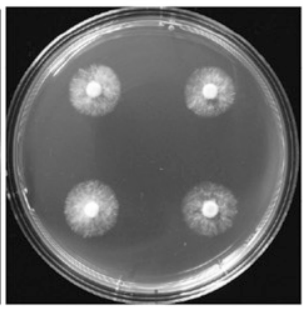

$\mathrm{H}_{2} \mathrm{O}_{2}(10 \mathrm{M})$

Fig. 5. Sensitivity of Sclerotinia homoeocarpa isolates to fungicides, osmotic stress, and oxidative stress. A, Sensitivity to different fungicides. 1, HRS10; 2 , HRI11; 3, HRS10(ShPDR1 ${ }^{\text {OX })-1 ; ~ 4, ~ H R S 10(S h P D R 1 ~}{ }^{\text {Ox })-2 ; ~ 5, ~ H R S 10(S h o s 11366 N)-1 ; ~ 6, ~ H R S 10(S h o s 1 ~ 1366 N)-2 ; ~ 7, ~ H R S 10(~} \Delta$ Shos1)-1; 8, HRS10( $\Delta$ Shos1)-2; 9, CT45; and 10, NY2. The pictures were taken after the isolates grew for $42 \mathrm{~h}$ on minimal medium (MM) without and with iprodione, vinclozolin, and fludioxonil. *The picture of plate with $1.5 \mu \mathrm{g} \mathrm{ml} \mathrm{l}^{-1}$ of iprodione were taken after $144 \mathrm{~h} .1$, HRS10; 2, HRI11; 3, HRS10(ShPDR1 ${ }^{\mathrm{OX}}$ )-1; and 4, HRS10(ShPDR1 ${ }^{\mathrm{OX}}$ )-2. B, Sensitivity to osmotic stress (generated by glucose, sorbitol, $\mathrm{NaCl}$, and $\mathrm{KCl}$ ) and oxidative stress (generated by $\mathrm{H}_{2} \mathrm{O}_{2}$ ). $1, \mathrm{HRS} 10 ; 2, \mathrm{HRS} 10(\mathrm{ShPDR} 1$ Ox)-1; 3 , $\operatorname{HRS10}\left(\operatorname{Shos}_{1} 1^{1366 \mathrm{~N}}\right)-1$; and $4, \operatorname{HRS10}(\Delta \mathrm{Shos} 1)-1$. The pictures were taken after the isolates were grown for $62 \mathrm{~h}$ on $\mathrm{MM}$ without and with glucose, sorbitol, NaCl, $\mathrm{KCl}$, and $\mathrm{H}_{2} \mathrm{O}_{2}$. 
HRS10 and HRS10( $\triangle$ Shos1)-1; however, ShHogl expression was up-regulated in HRS10(Shos $\left.1^{1366 N}\right)-1$ by 1.6 fold (Fig. 6).

\section{DISCUSSION}

This study reports both qualitative and quantitative types of iprodione resistance in $S$. homoeocarpa field isolates, i.e., an amino acid substitution in the HK gene Shos 1 and the overexpression of the ABC transporter gene ShPDRl, respectively. Specifically, the isolates examined in this study with the highest iprodione $\mathrm{EC}_{50}$ values contain the two aforementioned factors, and the MDR-like isolates exhibiting lower levels of iprodione resistance exhibit quantitative overexpression of the ShPDRl only. Our findings were validated by an analysis of Shos $1^{\mathrm{I} 366 \mathrm{~N}}, \triangle \mathrm{Shos} 1$, and ShPDR1 overexpression mutants from a dicarboximide-sensitive isolate. The Shos $1^{1366 \mathrm{~N}}$ mutants exhibiting resistance to iprodione indicated that the mutation $(\mathrm{I} 366 \mathrm{~N})$ is a qualitative determinant of iprodione resistance, and ShPDR1 overexpression mutants revealed that the level of ShPDRI expression contributes to a quantitative determent of reduced iprodione sensitivity.

In dicarboximide field-resistant isolates, an amino acid substitution at codon 366 in Shos1, from a hydrophobic isoleucine to a hydrophilic asparagine, resulted in decreased hydrophobicity in the region of this residue. So, it is plausible that the binding affinity of dicarboximide fungicides to Shos 1 is affected directly. The I366 N mutation does not affect the sensitivity of $S$. homoeocarpa to fludioxonil and osmotic stress, which suggests the effect of mutation is likely specific to dicarboximides. On the other hand, the Shos 1 deletion mutants exhibited a higher level of resistance to dicarboximide fungicides than Shos $1^{\mathrm{I} 366 \mathrm{~N}}$ mutants and resistant to a fludioxonil fungicide as well. The resistant phenotype to both fungicides has been reported in class III HK deletion mutants in many other fungal species, Neurospora crassa, Magnaporthe grisea, Cochliobolus heterostrophus, B. cinerea, and Sclerotinia sclerotiorum (Duan et al. 2013; Fujimura et al. 2000; Motoyama et al. 2005; Schumacher et al. 1997; Viaud et al. 2006; Yoshimi et al. 2004). Additionally, the Shos1-knockout mutants showed a strong growth reduction on polyols (sorbitol and glucose) but not on salt $(\mathrm{NaCl}$ and $\mathrm{KCl})$ (Fig. 5). The $\mathrm{HK}$ deletion mutants exhibited differing osmotic stress sensitivities based on fungal species (Duan et al. 2013); however, there is little understanding of the biological or ecological reasons regarding these differential osmotic stress sensitivities. For example, the mutants of Magnaporthe oryzae and Fusarium oxysporum show a higher sensitivity to polyol stress than to salt (Motoyama et al. 2005; Rispail and Pietro 2010), but the mutants of Neurospora crassa, Cochliobolus heterostrophus, B. cinerea, and Sclerotinia sclerotiorum display increased sensitivity to salt stress rather than to polyols (Alex et al. 1996; Duan et al. 2013; Viaud et al. 2006; Yoshimi et al. 2004). For oxidative stress, gene inactivation of Shk1 from Sclerotinia sclerotiorum confers hypersensitivity to $\mathrm{H}_{2} \mathrm{O}_{2}$ (Duan et al. 2013), whereas the HK deletion mutants in $B$. cinerea and $S$. homoeocarpa did not exhibit increased sensitivity to oxidative stress (Viaud et al. 2006) (Fig. 5). In addition, the HKs in Fusarium oxysporum, B. cinerea, and Alternaria brassicicola are required for full pathogenicity (Cho et al. 2009; Rispail and Pietro 2010; Viaud et al. 2006) but not in $S$. homoeocarpa, like Magnaporthe grisea and Sclerotinia sclerotiorum (Duan et al. 2013; Motoyama et al. 2005). Although $S$. homoeocarpa is closely related to Sclerotinia sclerotiorum and $B$. cinerea, the function of $\mathrm{HK}$ in osmotic and oxidative stresses and virulence shares or differs among these fungal species.

The present study provided further insight on the mechanisms of differential sensitivity of Shos $1^{\mathrm{I} 366 \mathrm{~N}}$ and Shos1-knockout mutants to iprodione by quantifying the expression of ShHogl. The increased iprodione resistance level in the Shos1 deletion mutant over the Shos $1^{1366 \mathrm{~N}}$ mutant was correlated with the decreased iprodioneinduced ShHogl expression (Figs. 5 and 6). Since HK is the upstream factor in an osmotic signaling system, the mutants lacking HK do not exhibit phosphorylation of HOG mitogen-activated protein kinase (MAPK) caused by fungicides (Tanaka and Izumitsu 2010; Yoshimi et al. 2005). In addition, translocation of phosphorylated Hog1 to the nucleus is preceded by the increased expression of the Hogl gene (Marques et al. 2006). The dicarboximide mode of action suggested by Tanaka and Izumitsu (2010) was that the fungicide targeting HK induces abnormal phosphorylation of the HOG1 MAPK, which alters downstream gene expression. Therefore, the Shos 1 deletion mutant may not affect expression or phosphorylation of ShHogl after exposure to iprodione, resulting in high resistance to iprodione. On the other hand, the Shosl ${ }^{\mathrm{I} 366 \mathrm{~N}}$ mutant was still able to regulate ShHogl expression but less than the wild strain. Therefore, lower levels of improper hogl-downstream gene expression may occur in response to iprodione. In order to fully understand the function of the mutation (I366N) and HK in S. homoeocarpa, further studies on the manipulation of genes from the HOG pathway, such as homologous genes of $B$. cinerea (BcSakl, BcOs4, BcOs5, BcRrgl, and $B c S k n 7$ ) (Liu et al. 2008; Segmüller et al. 2007; Yan et al. 2010, 2011; Yang et al. 2012, 2015) and downstream genes of the pathway are required.

From the data presented, six of seven dicarboximide-resistant isolates of S. homoeocarpa with the I366 N substitution in Shos I exhibited constitutive and induced overexpression of ShPDRl. Dicarboximide-resistant isolate NY2 had the lowest level of insensitivity to iprodione among dicarboximide-resistant isolates and did not exhibit induced expression of ShPDRl (Fig. 3). The Shos $1^{1366 N}$ mutants that did not overexpress ShPDRl also exhibited a lower iprodione resistance level than the iprodione-resistant isolate (CT45) that contained both resistance factors (Fig. 5). Furthermore, overexpression of ShPDRl in a sensitive isolate resulted in reduced sensitivity to iprodione (Fig. 5). These results suggest ShPDRI overexpression may play a role in the additive or quantitative resistance development in dicarboximide-resistant isolates but contributes less than the I366 N substitution in Shos1. However, additional studies are needed to test these hypotheses, using a larger and more diverse pool of dicarboximide-resistant field isolates.

This study and our previous studies, which have investigated the genetic determinants of MDR and DMI resistance (Hulvey et al.

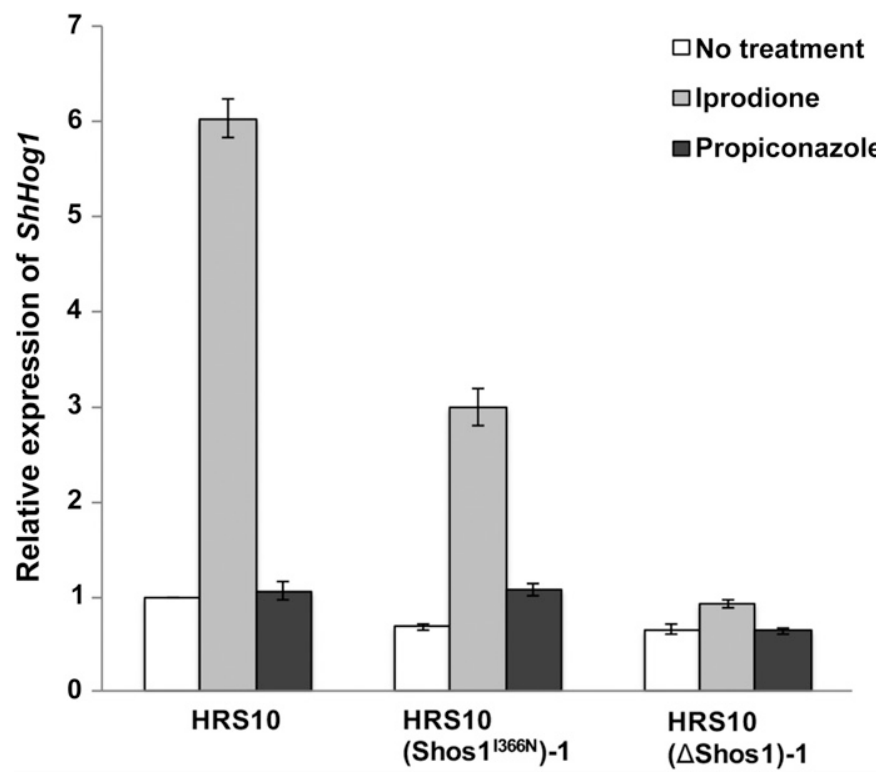

Fig. 6. Relative expression (RE) of ShHog 1 in HRS10, HRS10(Shos $\left.1^{1366 N}\right)-1$, and $\operatorname{HRS} 10(\Delta$ Shos 1$)-1$ before and after treatment with iprodione $\left(10 \mu \mathrm{g} \mathrm{ml}^{-1}\right)$ and propiconazole $\left(1 \mu \mathrm{g} \mathrm{ml}^{-1}\right)$ for $1 \mathrm{~h}$. White bars indicate mean constitutive RE values, light gray bars indicate mean iprodione-induced RE values, and dark gray bars indicate mean propiconazole-induced RE values. Error bars represent one standard error from the mean. 
2012; Sang et al. 2015), indicate that $S$. homoeocarpa has evolved multiple mechanisms of resistance to a specific fungicide and multiple fungicides. Understanding the mechanisms of fungicide resistance in this pathogen contributes to the information for evolution of other sterile fungi. This study also illustrated the use of a PEG-mediated protoplast transformation system in $S$. homoeocarpa for the first time and this methodology could be utilized to study the genetics and biology of $S$. homoeocarpa with the recent release of transcriptomic and genomic sequences of S. homoeocarpa (Green et al. 2016; Hulvey et al. 2012; Orshinsky et al. 2012). Our findings indicate that either the I366 N mutation in Shos 1, overexpression of ShPDR1, or both are conferring in vitro iprodione resistance but not pathogenicity; however, we have not confirmed to what extent these genetic determinants are associated with decreased iprodione field efficacy, which is under investigation. Findings from this study will be utilized for developing a molecular diagnostic tool for detection of iprodione resistance, which will help management of dollar spot on golf courses.

\section{ACKNOWLEDGMENTS}

We appreciate the generosity of A. I. Putman from University of California, Riverside for providing some of the $S$. homoeocarpa isolates used in this study. We thank our lab members, E. Allan, J. Stoner, and A. Ooi for careful review of this manuscript and thank V. Palanukorn for help with the protoplast preparation. This material is based upon work supported by the National Institute of Food and Agriculture (NIFA), United States Department of Agriculture (USDA), the Massachusetts Agricultural Experiment Station, and the Stockbridge School of Agriculture at the University of Massachusetts Amherst, under project number MAS00436. The contents are solely the responsibility of the authors and do not necessarily represent the official views of the USDA or NIFA.

\section{LITERATURE CITED}

Alex, L. A., Borkovich, K. A., and Simon, M. I. 1996. Hyphal development in Neurospora crassa: Involvement of a two-component histidine kinase. Proc. Natl. Acad. Sci. U.S.A. 93:3416-3421.

Beever, R. E., and Brien, H. M. R. 1983. A survey of resistance to the dicarboximide fungicides in Botrytis cinerea. New Zeal. J. Agr. 26:391-400.

Bishop, P., Sorochan, J., Ownley, B. H., Samples, T. J., Windham, A. S., Windham, M. T., and Trigiano, R. N. 2008. Resistance of Sclerotinia homoeocarpa to iprodione, propiconazole, and thiophanate-methyl in Tennessee and northern Mississippi. Crop Sci. 48:1615-1620.

Cho, Y., Kim, K.-H., Rota, M. L., Scott, D., Santopietro, G., Callihan, M., Mitchell, T. K., and Lawrence, C. B. 2009. Identification of novel virulence factors associated with signal transduction pathways in Alternaria brassicicola. Mol. Microbiol. 72:1316-1333.

Cole, H. B., Taylor, B., and Duich, J. 1968. Evidence of differing tolerances to fungicides among isolates of Sclerotinia homoeocarpa. Phytopathology 58: 683-686.

Cui, W., Beever, R., Parkes, S., and Templeton, M. 2004. Evolution of an osmosensing histidine kinase in field strains of Botryotinia fuckeliana (Botrytis cinerea) in response to dicarboximide fungicide usage. Phytopathology 94:1129-1135.

Cui, W., Beever, R., Parkes, S., Weeds, P., and Templeton, M. 2002. An osmosensing histidine kinase mediates dicarboximide fungicide resistance in Botryotinia fuckeliana (Botrytis cinerea). Fungal Genet. Biol. 36:187-198.

Detweiler, A. R., Vargas, J. M. J., and Danneberger, T. K. 1983. Resistance of Sclerotinia homoeocarpa to iprodione and benomyl. Plant Dis. 67:627-630.

Duan, Y., Ge, C., Liu, S., Wang, J., and Zhou, M. 2013. A two-component histidine kinase Shkl controls stress response, sclerotial formation and fungicide resistance in Sclerotinia sclerotiorum. Mol. Plant Pathol. 14: 708-718.

Fillinger, S., Ajouz, S., Nicot, P., Leroux, P., and Bardin, M. 2012. Functional and structural comparison of pyrrolnitrin- and iprodione-induced modifications in the class III histidine-kinase Bos1 of Botrytis cinerea. PLoS One 7:e42520.

Fujimura, M., Ochiai, N., Ichiishi, A., Usami, R., Horikoshi, K., and Yamaguchi, I. 2000. Fungicide resistance and osmotic stress sensitivity in os mutants of Neurospora crassa. Pestic. Biochem. Physiol. 67:125-133.

Green, R., Sang, H., Chang, T., Allan-Perkins, E., Petit, E., and Jung, G. 2016. Draft genome sequences of the turfgrass pathogen Sclerotinia homoeocarpa. Genome Announc. 4:e01715-15.
Hulvey, J., Popko, J. T., Sang, H., Berg, A., and Jung, G. 2012. Overexpression of ShCYP51B and ShatrD in Sclerotinia homoeocarpa isolates exhibiting practical field resistance to a demethylation inhibitor fungicide. Appl. Environ. Microbiol. 78:6674-6682.

Hutton, D. G. 1988. The appearance of dicarboximide resistance in Alternaria alternata in passionfruit in south-east Queensland. Aust. Plant Path. 17:34-36.

Jo, Y., Niver, A., Rimelspach, J., and Boehm, M. J. 2006. Fungicide sensitivity of Sclerotinia homoeocarpa from golf courses in Ohio. Plant Dis. 90:807-813.

Katan, T. 1982. Resistance to 3,5-dichlorophenyl-N-cyclic imide ('dicarboximide') fungicides in the grey mould pathogen Botrytis cinerea on protected crops. Plant Pathol. 31:133-141.

Katoh, K., and Toh, H. 2008. Recent developments in the MAFFT multiple sequence alignment program. Brief. Bioinform. 9:286-298.

Koenraadt, H., Somerville, S. C., and Jones, A. 1992. Characterization of mutations in the beta-tubulin gene of benomyl-resistant field strains of Venturia inaequalis and other plant pathogenic fungi. Phytopathology 82:1348-1354.

Leroux, P., Fritz, R., Debieu, D., Albertini, C., Lanen, C., Bach, J., Gredt, M., and Chapeland, F. 2002. Mechanisms of resistance to fungicides in field strains of Botrytis cinerea. Pest Manag. Sci. 58:876-888.

Littley, E. R., and Rahe, J. E. 1984. Specific tolerance of Sclerotium cepivorum to dicarboximide fungicides. Plant Dis. 68:371-374.

Liu, W., Leroux, P., and Fillinger, S. 2008. The HOG1-like MAP kinase Sak1 of Botrytis cinerea is negatively regulated by the upstream histidine kinase Bos1 and is not involved in dicarboximide- and phenylpyrrole-resistance. Fungal Genet. Biol. 45:1062-1074.

Livak, K., and Schmittgen, T. 2001. Analysis of relative gene expression data using real-time quantitative PCR and the $2^{-\Delta \Delta C(T)}$ method. Methods 25:402-408.

Ma, Z., Luo, Y., and Michailides, T. 2006. Molecular characterization of the two-component histidine kinase gene from Monilinia fructicola. Pest Manag. Sci. 62:991-998.

Ma, Z., Yan, L., Luo, Y., and Michailides, T. J. 2007. Sequence variation in the two-component histidine kinase gene of Botrytis cinerea associated with resistance to dicarboximide fungicides. Pestic. Biochem. Physiol. 88: 300-306.

Marques, J. M., Rodrigues, R. J., de Magalhães-Sant'ana, A. C., and Gonçalves, T. 2006. Saccharomyces cerevisiae Hog1 protein phosphorylation upon exposure to bacterial endotoxin. J. Biol. Chem. 281:24687-24694.

Miller, G. L., Stevenson, K. L., and Burpee, L. L. 2002. Sensitivity of Sclerotinia homoeocarpa isolates to propiconazole and impact on control of dollar spot. Plant Dis. 86:1240-1246.

Mocioni, M., Gullino, M. L., and Garibaldi, A. 2011. Sensitivity of Sclerotinia homoeocarpa isolates from turfgrass in Italy to demethylation-inhibiting (DMI) fungicides and iprodione. Phytopathol. Mediterr. 50:408-413.

Motoyama, T., Kadokura, K., Ohira, T., Ichiishi, A., Fujimura, M., Yamaguchi, I., and Kudo, T. 2005. A two-component histidine kinase of the rice blast fungus is involved in osmotic stress response and fungicide action. Fungal Genet. Biol. 42:200-212.

Orshinsky, A., Hu, J., Opiyo, S., Reddyvari-Channarayappa, V., Mitchell, T., and Boehm, M. 2012. RNA-seq analysis of the Sclerotinia homoeocarpacreeping bentgrass pathosystem. PLoS One 7:e41150.

Oshima, M., Fujimura, M., Banno, S., Hashimoto, C., Motoyama, T., Ichiishi, A., and Yamaguchi, I. 2002. A point mutation in the two-component histidine kinase $B c O S-1$ gene confers dicarboximide resistance in field isolates of Botrytis cinerea. Phytopathology 92:75-80.

Popko, J. T., Ok, C., Campbell-Nelson, K., and Jung, G. 2012. The association between in vitro propiconazole sensitivity and field efficacy of five New England Sclerotinia homoeocarpa populations. Plant Dis. 96:552-561.

Putman, A. I., Jung, G., and Kaminski, J. E. 2010. Geographic distribution of fungicide-insensitive Sclerotinia homoeocarpa isolates from golf courses in the northeastern United States. Plant Dis. 94:186-195.

Rech, C., Engh, I., and Kück, U. 2007. Detection of hyphal fusion in filamentous fungi using differently fluorescence-labeled histones. Curr. Genet. 52:259-266

Rispail, N., and Pietro, D. A. 2010. The two-component histidine kinase Fhk1 controls stress adaptation and virulence of Fusarium oxysporum. Mol. Plant Pathol. 11:395-407.

Ritchie, D. 1983. Mycelial growth, peach fruit-rotting capability, and sporulation of strains of Monilinia fructicola resistant to dichloran, iprodione, procymidone, and vinclozolin. Phytopathology 73:44-47.

Rollins, J. A. 2013. The Sclerotinia sclerotiorum pacl gene is required for sclerotial development and virulence. Mol. Plant-Microbe Interact. 16:785-795.

Rozen, S., and Skaletsky, H. 2000. Primer3 on the WWW for general users and for biologist programmers. Methods Mol. Biol. 132:365-386.

Saitoh, K., Togashi, K., Arie, T., and Teraoka, T. 2006. A simple method for a mini-preparation of fungal DNA. J. Gen. Plant Pathol. 72:348-350.

Sang, H., Hulvey, J., Popko, J. T., Lopes, J., Swaminathan, A., Chang, T., and Jung, G. 2015. A pleiotropic drug resistance transporter is involved in reduced sensitivity to multiple fungicide classes in Sclerotinia homoeocarpa. Mol. Plant Pathol. 16:251-261. 
Schumacher, M. M., Enderlin, C. S., and Selitrennikoff, C. P. 1997. The osmotic-1 locus of Neurospora crassa encodes a putative histidine kinase similar to osmosensors of bacteria and yeast. Curr. Microbiol. 34:340-347.

Segmüller, N., Ellendorf, U., and Tudzynski, B. 2007. BcSAK1, a stressactivated mitogen-activated protein kinase, is involved in vegetative differentiation and pathogenicity in Botrytis cinerea. Eukaryot. Cell 6:211-221.

Smiley, R. W., Dernoeden, P. P., and Clarke, B. B. 2005. Compendium of turfgrass diseases. American Phytopathological Society, St. Paul, MN.

Tamura, K., Peterson, D., Peterson, N., Stecher, G., Nei, M., and Kumar, S. 2011. MEGA5: Molecular evolutionary genetics analysis using maximum likelihood, evolutionary distance, and maximum parsimony methods. Mol. Biol. Evol. 28:2731-2739.

Tanaka, C., and Izumitsu, K. 2010. Two component signaling system in filamentous fungi and the mode of action of dicarboximide and phenylpyrrole fungicides. Pages 523-538 in: Fungicides. O. Carisse, ed. InTech, Rijeka, Croatia.

Viaud, M., Fillinger, S., Liu, W., Polepalli, J., Le Pêcheur, P., Kunduru, A., Leroux, P., and Legendre, L. 2006. A class III histidine kinase acts as a novel virulence factor in Botrytis cinerea. Mol. Plant-Microbe Interact. 19:1042-1050.

Yan, L., Yang, Q., Jiang, J., Michailides, T. J., and Ma, Z. 2011. Involvement of a putative response regulator Brrg-1 in the regulation of sporulation, sensitivity to fungicides, and osmotic stress in Botrytis cinerea. Appl. Microbiol. Biotechnol. 90:215-226.
Yan, L., Yang, Q., Sundin, G. W., Li, H., and Ma, Z. 2010. The mitogenactivated protein kinase kinase BOS5 is involved in regulating vegetative differentiation and virulence in Botrytis cinerea. Fungal Genet. Biol. 47: 753-760.

Yang, Q., Yan, L., Gu, Q., and Ma, Z. 2012. The mitogen-activated protein kinase kinase kinase BcOs4 is required for vegetative differentiation and pathogenicity in Botrytis cinerea. Appl. Microbiol. Biotechnol. 96: 481-492.

Yang, Q., Yin, D., Yin, Y., Cao, Y., and Ma, Z. 2015. The response regulator $\mathrm{BcSkn} 7$ is required for vegetative differentiation and adaptation to oxidative and osmotic stresses in Botrytis cinerea. Mol. Plant Pathol. 16: 276-287.

Yoshimi, A., Kojima, K., Takano, Y., and Tanaka, C. 2005. Group III histidine kinase is a positive regulator of Hog1-type mitogen-activated protein kinase in filamentous fungi. Eukaryot. Cell 4:1820-1828.

Yoshimi, A., Tsuda, M., and Tanaka, C. 2004. Cloning and characterization of the histidine kinase gene Dic1 from Cochliobolus heterostrophus that confers dicarboximide resistance and osmotic adaptation. Mol. Genet. Genomics 271:228-236.

Yoshimura, M. A., Luo, Y., Ma, Z., and Michailides, T. J. 2004. Sensitivity of Monilinia fructicola from stone fruit to thiophanate-methyl, iprodione, and tebuconazole. Plant Dis. 88:373-378. 